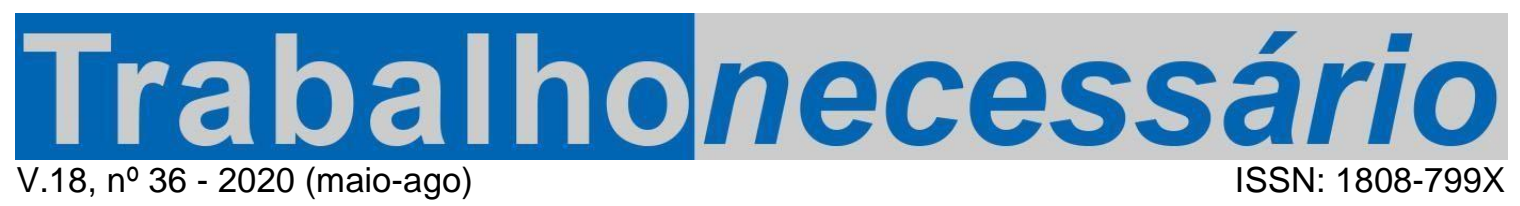

\title{
MUJERES EN LUCHA POR LA DEFENSA DE LA VIDA ASEDIADA Y AFECTADA POR LOS EXTRACTIVISMOS EN MÉXICO ${ }^{1}$
}

\author{
Mina Lorena Navarro Trujillo²
}

Por la memoria viva de Guadalupe Campanur, comunera de Cherán

\begin{abstract}
Resumen
En la intensa conflictividad socioecológica, que en los últimos 20 años, en México y en América Latina, se viene experimentando por la extensión e intensificación de las lógicas extractivistas de valorización sobre los cuerpos, territorios y fuentes de vida, rastreo la emergencia de una politicidad protagonizada por mujeres en lucha para garantizar la sostenibilidad y la reproducción de la vida en sus territorios, contra toda clase de asedios y afectaciones ecosistémicas.

Palabras clave: Mujeres; protagonismo femenino; defensa de la vida; extractivismo; violencia.

\section{MULHERES EM LUTA PELA DEFESA DA VIDA COLOCADA E AFETADA PELOS EXTRACTIVISMOS NO MÉXICO}

\section{Resumo}

No intenso conflito socioecológico, que nos últimos 20 anos, no México e na América Latina, vem-se experimentando pela extensão e intensificação das lógicas extrativistas de valorização sobre os corpos, territórios e fontes de vida, analiso a emergência de uma ação política protagonizada por mulheres em luta para garantir a sustentabilidade e a reprodução da vida em seus territórios, contra todo tipo de assédios e ataques ecosistêmicos.

Palavras-Chave: Mulheres; protagonismo feminino; defesa da vida; extrativismo; violência.

\section{WOMEN IN STRUGGLE FOR THE DEFENSE OF THE LIFE PLACED AND AFFECTED BY EXTRACTIVISMS IN MEXICO}

\begin{abstract}
In the intense socio-ecological conflict, that in the past 20 years, in Mexico and Latin America, has been being experimented by the extension and intensification of the extractivists logics of valuation of bodies, territories and founts of life, I analyze the emergency of a political action protagonized by women in fight to guarantee the sustainability and the reproduction of life in their territories, against all types of assaultment and eco-systemics affectations
\end{abstract}

Key-words: Women; feminine protagonism; defense of life; extractivism; violence.

\footnotetext{
${ }^{1}$ Artigo recebido em 30/10/2019. Primeira avaliação em 30/01/2020. Segunda avaliação em 31/01/2020. Aprovado em 08/04/2020. Publicado em 22/05/2020. DOI: https://doi.org/10.22409/tn.v18i36.38360

2 Doctora en Sociología y Profesora-investigadora del Instituto de Ciencias Sociales y Humanidades "Alfonso Vélez Pliego" de la Benemérita Universidad Autónoma de Puebla (BUAP), México. Correo electrónico: mlorena.navarrot@gmail.com. ORCID: 0000-0002-5466-9282
} 


\section{Introducción}

El 19 de enero de 2018 salió a la luz pública la noticia de que Guadalupe Campanur, mujer p'urhépecha, comunera en defensa de la vida y de los bosques y participante de la lucha por la autonomía de Cherán, en el centro-oeste del territorio mexicano, había sido torturada sexualmente y encontrada sin vida, en el municipio de Chilchota en Michoacán. La noticia me cimbró y angustió. Yo no la conocía personalmente, aunque su nombre lo había escuchado, en las distintas menciones al importante rol que las mujeres de Cherán han jugado en el proceso autonómico de su territorio y sus modos tan audaces de poner el cuerpo para poner un límite a la explotación de su bosque y la violencia de los talamontes y el crimen organizado.

Días después, Carolina Márquez, una amiga muy cercana a Lupe, -como su red de familiares y amigos, le decían-, nos convocó a sumarnos a la Campaña \#JusticiaParaLupita \#TodasSomosLupeCampanur ¡Nuestra lucha es por la vida!, llamando a que su feminicidio no quedara impune, que la justicia se apegara a los protocolos internacionales, a que no se minimizara su feminicidio por enjuiciar moralmente su vida y solicitando protección para todas las personas cercanas, dispuestas a contribuir con el esclarecimiento de los hechos. Adicionalmente, nos convocó el 18 de febrero, un mes después de su asesinato, y sucesivamente cada mes, a que todas las que pudiéramos nos encontráramos en nuestros territorios para "Bordar su nombre", como "una manera de dignificar su vida, de exigir justicia y al mismo tiempo, de conectarnos con algo que ella disfrutaba, como era el bordado". Como muchas otras colectividades lo vienen haciendo en todo el país a partir de la muerte y desaparición de sus seres queridos por la llamada "Guerra contra el narcotráfico", la convocatoria a bordar en esta ocasión, también era una forma de tejer un vínculo colectivo capaz de habilitar la palabra y la escucha, y sostener una lucha por la justicia y contra el olvido de Lupe.

En Puebla, en el centro de México, desde el Seminario de Entramados Comunitarios y Formas de lo Político ${ }^{3}$, profesoras y estudiantes nos sumamos al llamado

\footnotetext{
${ }^{3}$ Comunidad de trabajo y espacio permanente de investigación que coordino junto con Raquel Gutiérrez y Lucia Linsalata, con sede en el Posgrado de Sociología del Instituto de Ciencias Sociales y Humanidades de la Benemérita Universidad Autónoma de Puebla (BUAP), en la ciudad de Puebla, México.
} 
de "Bordar su nombre" y decidimos lanzar un espacio de pensamiento colectivo con amigas de Lupe, compañeras de Radio Comunitaria Zacatepec, las y los Defensores del Río Ajajalpan y de Makxtum Kgalhaw, -luchas en defensa de la vida de la Sierra Norte de Puebla- y compañeras investigadoras que vienen reflexionando sobre las violencias contra las mujeres en México. ${ }^{4}$ Así, El 22, 23 y 24 de agosto de 2018, nos reunimos en el "Encuentro de Entrelazamiento desde la Reflexión: Mujeres en defensa de la vida y contra las violencias y los despojos múltiples. En memoria de Lupe Campanur, a 7 meses de su femincidio". Durante esos días, a partir de bordar su nombre, pensarla y evocarla, exploramos la importancia de poner en común nuestras experiencias y conocimientos para producir una mirada que, en medio de la fragmentación y la separación de las luchas entre el campo y la ciudad, conectara las distintas violencias que nos afectan y contra las que nos defendemos y luchamos. En lo indivisible de la violencia, reconocimos la dimensión común de nuestras luchas y la importancia de extendernos entre puentes. También, encontramos palabras para nombrar los agravios y ensayamos formas de enunciar y elaborar los dolores debajo de la piel. Mover el dolor y "ponerlo a trabajar" nos conectó con una forma de politizar nuestra vulnerabilidad y abrir un más allá del impotente y desolado lugar de la víctima. Intercambiamos modos de reconocer y desactivar los mandatos y los pactos patriarcales que buscan codificar en clave de culpa nuestros deseos, desacatos y el sentido libertario de nuestras acciones. Al momento de preguntarnos por la justicia que necesitamos, coincidimos que la producción de sentido es un terreno estratégico de la disputa, por lo que es vital poner en juego nuestras capacidades para nombrar, interpretar lo sucedido y tejer una memoria crítica desde nuestras indisciplinas y rebeldías.

Siguiendo el hilo de lo que en aquellos días conversamos, en este texto me propongo analizar algunas de las aristas de las múltiples luchas que las mujeres están desplegando en sus territorios, para enfrentar las lógicas violentas y depredadoras contra ellas y sus tramas de interdependencia. En particular, exploro la producción de un protagonismo femenino en las luchas socioecológicas, encarnado en aquellas mujeres que defienden sus territorios amenazados y afectados por las lógicas extractivistas de

\footnotetext{
${ }^{4}$ En particular agradezco a Carolina Márquez, Raquel Gutiérrez, Lucia Linsalata, Ana Laura Suárez, Emanuela Borzacchiello y Natalia De Marinis por su colaboración en la construcción de este encuentro.
} 
valorización.

Para lograr lo anterior, busco comprender las condiciones históricas de la conflictividad en las que se inscriben y despliegan estas luchas, analizando la relación entre extractivismo y violencia. Me interesa saber cómo la violencia, como parte de un complejo capitalista-patriarcal y colonial, se intersecta con las necesidades de la acumulación del capital en los territorios amenazados y afectados por el extractivismo. El entendimiento de estas condiciones se cruza con el esfuerzo por explorar las capacidades políticas de las mujeres en lucha y los alcances por conservar y también transformar la interdependencia en sus tramas comunitarias y territorios de vida.

\section{Violencia y regímenes extractivistas en la geografía del Abya Yala}

La actual ofensiva extractivista (SEOANE, 2012, 123) que hoy asedia los territorios y medios de vida, tiene profundas raíces históricas, que se remontan a los tiempos de la conquista y al saqueo de Abya Yala, pero que claramente en las últimas dos décadas se ha intensificado en todos los países de América Latina, con el llamado Consenso de los Commodities (Svampa, 2013) ${ }^{5}$, profundizando aun más la posición colonial, periférica, dependiente y subordinada del continente en el sistema mundo (MACHADO, 2016).

Los regímenes extractivistas, como lo propone Horacio Machado, son aquellas formaciones socio-geo-económicas en las que la sobre-explotación exportadora de naturalezas 6 se erige como el principal patrón organizador y regulador de las estructuras económicas, socioterritoriales y de poder. Esta lógica de acumulación involucra una forma política de control, dominio y disposición de los territorios (MACHADO, 2019), capaz de garantizar la extracción intensiva y a gran escala grandes volúmenes de bienes primarios (petróleo, gas, minerales, monocultivos) para ser exportados generalmente al mercado internacional, sin procesamientos previos significativos. Tendiente a la

\footnotetext{
${ }^{5}$ El consenso de los Commodities, a partir del 2000- 2003, se basa en la exportación a gran escala de bienes primarios, el crecimiento económico y la expansión del consumo, en el contexto en el que las economías latinoamericanas fueron favorecidas por los altos precios internacionales de los productos primarios (commodities), todo lo cual se vio reflejado en las balanzas comerciales y el superávit fiscal.

${ }^{6}$ Hablo de naturalezas en plural (naturalezas humanas y no humanas), porque siguiendo a Jason Moore (2015) se trata de pensar más allá de la bipolaridad Sociedad + Naturaleza, buscando colocar la comprensión de lo humano como naturaleza y la relación de interdependencia intrínseca que guarda con la biósfera para garantizar su sostenimiento.
} 
monoproducción y a la expansión de las fronteras extractivas, esta lógica de acumulación al estar dislocada de las necesidades locales, desarticula las economías de sustento y formas autónomas de apropiación y gestión de la riqueza social. Generalmente, impone economías de enclave, que funcionan como 'islas' con escasas relaciones y vinculaciones con las cadenas industriales nacionales, ya que buena parte de sus insumos y tecnologías son importados y el personal técnico requerido es extranjero. Esta dinámica, supeditada a cubrir los requerimientos y demandas de otras regiones del planeta, enriquece esencialmente a las casas matrices de los capitales nacionales y trasnacionales beneficiados (GUDYNAS, 2013).

La violencia y el despojo son los mecanismos que aceitan este modo de acumulación. Si bien en las narrativas dominantes, estos "métodos" aparecen como colaterales, excepcionales, anómalos, accidentales o fallos del mercado o del Estado, lo cierto es que el capitalismo históricamente ha respondido a una dinámica de apropiación, explotación y externalización de los ámbitos no mercantilizados del tejido de la vida para convertirlos en valor y garantizar su propia reproducción.

Por distintos caminos, tanto el Ecofeminismo, la Economía Feminista y la Economía Ecológica han llamado la atención sobre las formas en las que la dinámica capitalista "externaliza" los costos socioecológicos, o dicho en otras palabras, invisibiliza la violencia y sus lógicas destructivas, al menor costo posible. En la Economía neoclásica, las llamadas externalidades no son otra cosa que los costos ambientales que no son contemplados en el cálculo costo-beneficio de los procesos de producción, pero lo cierto es que hacen parte de un régimen de ocultamiento para la desvalorización del trabajo y energía explotada de las mujeres, de los hombres campesinos y esclavos en las colonias y las naturalezas no humanas, a partir de presentarlos como "no productivos" y por fuera de la "economía real".

Como lo señala Maria Mies, "en el transcurso de los últimos cuatro o cinco siglos, las mujeres, la naturaleza y las colonias han sido externalizadas -declarándolas ajenas a la sociedad civilizada-, al tiempo que se han visto empujadas a la oscuridad, invisibilizadas como si fueran parte sumergida de un iceberg, que resulta invisible, aunque constituyan la base del resto" (MIES, 2019, 156).

En un trabajo con Claudia Composto, exploramos los dispositivos legales, de 
producción de sentido, institucionales, de disciplinamiento, de contrainsurgencia, que en contextos de despojo por proyectos de megaminería, hacen posible la transferencia de estas violencias. Constatamos que no es casualidad que la producción de sentido de gobiernos y empresas presente a los territorios de extracción como "espacios" pobres, ociosos, vacíos, ausentes de la presencia del Estado y de una política de desarrollo, y por ende, necesarios de insertar en el proceso de modernización y progreso (COMPOSTO, NAVARRO, 2014).

Tras el telón del desarrollo, la promesa de generación de empleos, el beneficio de la inversión extranjera y la modernización en marcha, las luchas en defensa de la vida, han logrado evidenciar que la acumulación del capital es violenta y destructiva de los cuerpos y territorios. Los habitantes no viven mejor con la llegada de la industria y los demás megaproyectos implementados o en promesa de desarrollarse, por el contrario, territorios intoxicados como el del Salto en la zona metropolitana de Guadalajara, en el occidente de México, han venido enfrentando lo que Enrique Enciso, ha llamado un Chernobyl en cámara lenta (FISHER Y MALKIN, 2020) que no es otra cosa que un proceso de despojo paulatino de los medios de vida indispensables para garantizar una subsistencia sana y digna, así como de desastre, enfermedad y degradación biocida de las capacidades autoregulativas de los habitantes y sus ecosistemas.

El planteamiento que Naomi Klein ha venido construyendo sobre el capitalismo de desastre (2020), sugiero puede servirnos para entender cómo las industrias privadas surgen a partir de crear procesos de crisis, sacar partido y beneficiarse directamente de los estados de emergencia socioambiental de los territorios afectados y asediados. Como han sugerido lúcidamente las y los integrantes de la Agrupación Un Salto de Vida, "la contaminación es un buen negocio" (NAVARRO, 2015).

Lo cierto es que en los últimos 5 siglos, asistimos al avance de un proceso civilizatorio capitalista-patriarcal y colonial, a partir de reducir la complejidad socioecológica y convertir los dualismos y las diferencias en jerarquías, imponiendo una visión binaria que niega la pluralidad y organiza el mundo en pares antagónicos, opuestos, excluyentes y no simultáneos, (cultura- naturaleza, hombre-mujer, masculinofemenino, producción- reproducción, racionalidad-mente, afectividad-cuerpo, públicoprivado, razón- práctica), inaugurando y justificando relaciones opresivas de erradicación, 
inferiorización, devaluación, naturalización y feminización (SEGATO, 2016; FRAGA, 2013).

Así, el rasgo determinante de la modernidad son las sucesivas 'separaciones' o 'particiones' del mundo de lo 'real' (LANDER, 2003; DE ANGELIS, 2012; NAVARRO Y GUTIÉRREZ, 2018), esto es, la separación del orden humano del resto de las especies no humanas, mediante el despliegue de una racionalidad contra natura, de la mano de la ciencia y la tecnología, en la que la llamada naturaleza ha quedado codificada como objeto colonial de dominio y materia prima del proceso productivo, desconociéndose su orden complejo y ecosistémico (LEFF, 2006). Simultáneamente, se han impuesto relaciones de subordinación sexo- genéricas, en la que las mujeres, a través del proceso de caza de brujas y la imposición de la pinza matrimonio-familia, como rígida organización heteronormada de la reproducción social (GUTIÉRREZ, 1999; TZUL, 2016), han quedando confinadas al ámbito reproductivo y despojadas de sus creaciones y expropiadas de sus conocimientos y capacidades políticas en la gestión de la reproducción de la vida (FEDERICI, 2013; GUTIÉRREZ, REYES, SOSA, 2017), lo que es parte de una gran proceso de separación de las tramas comunitarias de sus medios de existencia y su consecuente explotación como trabajadores formalmente libres y proletarizados.

Llegado este punto, resulta evidente que el análisis de los actuales regímenes extractivistas en América Latina, como densas formaciones socio-geo-económicas, no puede desligarse de la estructuración histórica y a la vez actualizada de este complejo civilizatorio de violencia capitalista-patriarcal y colonial.

Desde esta perspectiva, diríamos que la actualidad de los regímenes extractivistas en los tiempos de la acumulación en su fase neoliberal, se basa en la intensificación de las dinámicas de mercantilización mediadas por múltiples y crecientes recursos de violencia y el reforzamiento del poder de la clase capitalista, estructurada en un complejo institucional que abarca a Estados, grandes corporaciones transnacionales y organismos multilaterales, los cuales funcionan bajo la subordinación estricta del capital financiero, al que responden como sus resortes gerenciales (MACHADO, 2019, 9 y DUMÉNIL Y LÉVY, 2012, citado en: MACHADO, 2019).

Desde esa lógica, los gobiernos latinoamericanos, más allá de su signo político, 
han buscado garantizar la extracción de materia y energía que satisfaga las necesidades de las dinámicas capitalistas, apelando discursivamente al enaltecimiento del extractivismo como vía necesaria para que las naciones abandonen su condición de subdesarrollo y se integren a la modernización en marcha. La exportación de bienes primarios es la ventaja comparativa que hay que aprovechar, reza la consigna, sin importar los costos socioecológicos, externalizados que muy prontamente han podido verificarse en los procesos de desposesión y desplazamiento de las poblaciones y en la degradación irreversible de los territorios sacrificados (NAVARRO, 2015).

El correlato de esta tendencia predatoria, -oscurecida por una narrativa que promueve y enaltece la magia de un desarrollo sin consecuencias-, es la emergencia de un tejido de luchas contra el extractivismo que vienen visibilizando y denunciando las afectaciones socioecológicas de este patrón productivo sobre sus modos y medios de vida. A través de estas voces se viene constatando la relación directamente proporcional entre violencia y extractivismo, que se evidencia en la degradación biocida de las capacidades autoregulativas de la trama de la vida, en la desestructuración del tejido social e instancias comunitarias para decidir y normar la vida colectiva, el despojo de medios de vida para garantizar la subsistencia, la polarización y división al interior de los entramados comunitarios, el endurecimiento de los contextos de criminalización, el incremento de los asesinatos a activistas ambientales, la violencia machista contra las mujeres y el recrudecimiento de formas patriarcales de dominación y opresión (COMPOSTO, NAVARRO, 2014; CARVAJAL, 2016; GUTIÉRREZ Y NAVARRO, 2019).

En México, esta violencia se ha intensificado en los últimos años con la llamada "Guerra contra el narcotráfico" iniciada por Felipe Calderón, y continuada por Enrique Peña Nieto. Actualmente con el gobierno de la Cuarta Transformación, está por verse cómo se hace efectivo "el fin de la guerra contra las drogas" anunciado en el Plan Nacional de Desarrollo 2019-2024" y los resultados de las políticas de prevención del delito, justicia transicional y la creación de la Guardia Nacional, que hasta el momento ha sido duramente cuestionado por las organizaciones de víctimas y de derechos humanos. En este contexto, miles de familiares han estado exigiendo al Estado mexicano, la búsqueda y aparición con vida de las más de 61 mil víctimas de desaparición forzada, desde el 2006, según lo reporta el nuevo Registro Nacional de Personas Desaparecidas 
y No Localizadas (RNPDNO).

En el marco de esta guerra, se hace cada vez más visible la alarmante escalada de violencia estatal y paraestatal contra las y los defensores de aquellos territorios 0 medios de vida asediados. En su más reciente informe, Global Witness da cuenta en 2016 de, por lo menos 200 personas defensoras asesinadas, mayoritariamente indígenas de América Latina, por conflictos ligados al sector de la minería. Esta misma organización señala que lamentablemente no se produce suficiente información desagregada sobre el número de mujeres defensoras de los territorios que son víctimas de ataques por su labor, pero que sin embargo, es claro que sufren impactos diferenciados y que el escarmiento comunitario que se experimenta con ocasión de dichos ataques, requiere de una mayor atención (Global Witness, 2017). En el Informe del Relator Especial sobre la situación de los defensores de los derechos humanos, presentado en 2016 a la Asamblea General de las Naciones Unidas se señala que las defensoras,

se enfrentan a una serie de desafíos, incluidos los relacionados con la exclusión de la participación en los procesos de negociación y adopción de decisiones; la criminalización, que se utiliza como estrategia política para impedir la resistencia y deslegitimar su labor; las campañas de desprestigio contra ellas en los medios de comunicación; y la discriminación y violencia que sufren en el seno de sus familias, sus comunidades y en los movimientos en favor de los derechos humanos.

Dentro de los casos de violencia más extrema contra mujeres defensoras de sus territorios en América Latina, se encuentra el brutal asesinato de Berta Cáceres, mujer indígena lenca, asesinada el 3 de marzo de 2016, en el contexto de la resistencia de su pueblo y del Consejo Cívico de Organizaciones Populares e Indígenas de Honduras (COPINH) a la implementación del proyecto hidroeléctrico Agua Zarca. Nilce de Souza, referente del Movimiento de las Personas Afectadas por las Represas (MAB), de Brasil, desapareció el 7 de enero de 2016 en Paraná, y su cuerpo fue encontrado cinco meses después en el lago construido por la presa con signos de violencia. El feminicidio ocurre en el contexto de resistencia a los impactos de la Hidroeléctrica Jirau. Macarena Valdés, asesinada el 22 de agosto de 2016, aunque las autoridades policiales se precipitaron en presentar el caso como un suicidio, su asesinato se trató de un feminicidio ocurrido por su liderazgo en la resistencia comunitaria a la instalación de redes eléctricas de la Empresa Austro-chilena RP Global Chile Energías Renovables S.A (CARVAJAL, 2016, 
16-18). Maricela Tombé asesinada en 2016, secretaria de la Junta de Acción Comunal de la vereda Brisas, y presidenta de la Asociación Campesina Ambiental de Playa Rica (Ascap), de El Tambo, Colombia. Yaneth Alejandra Calvache Viveros, integrante de la Asociación de Trabajadores Campesinos de Balboa, Cauca Colombia, fue asesinada en 2016 por desconocidos en su casa. Bernicia Dixon Peralta de la comunidad indígena Miskitu asesinada en 2016 en medio de un conflicto por el desconocimiento oficial de la propiedad indígena sobre sus tierras ancestrales en Nicaragua (Global Witness, 2017).

En México, entre los casos más conocidos de violencia extrema, hacia mujeres vinculadas con alguna lucha en defensa del territorio, se encuentra el de Alberta "Bety" Cariño asesinada en 2010, cuando los paramilitares emboscaron la caravana en la que ella participaba junto con el activista finlandés, Jyri Antero Jaakkola, también acaecido, en su camino a la comunidad indígena autónoma de San Juan Copala, que había estado bajo un bloqueo de los paramilitares aliados con el gobierno del estado de Oaxaca, en el sur de México (SALAZAR, 2016). En 2012, Fabiola Osorio Bernáldez, integrante de la organización Guerreros Verdes, fue asesinada por un grupo de hombres armados que llegó a su domicilio y la acribilló junto con una vecina que se encontraba con ella. Fabiola había participado férreamente contra la construcción del proyecto turístico, Muelle de Pie de la Cuesta, a desarrollarse en un manglar de la Laguna de Coyuca, bello refugio natural a 22 km del Puerto de Acapulco, en el sur del territorio mexicano (El País, 2012). En 2012 Juventina Villa Mojica, dirigente de la Organización de Campesinos Ecologistas de Petatlán y Coyuca de Catalán del estado de Guerrero, fue asesinada junto con su hijo de 17 años por un grupo de 30 a 40 hombres armados. Su asesinato ocurrió cuando pretendía encabezar el éxodo de 45 familias de La Laguna que se desplazarían a la comunidad de Puerto de las Ollas, a fin de refugiarse del acoso al que habían estado sometidas por paramilitares y talamontes (OCAMPO, 2012). En enero del 2018, el ya mencionado feminicidio de María Gudalupe Campanur Tapia, comunera del municipio autónomo de Cherán (DELLA COLLETA, 2018). Y más recientemente, Paulina Gómez, defensora del territorio sagrado de Wirikuta y amiga del pueblo wixárika en la batalla contra el emprendimiento minero de First Majestic Silver Corporation en la región centro del país, fue encontrada asesinada el 22 de marzo de 2020 con una herida de bala en el rostro (La Jornada Zacatecas, 2020). 
En definitiva, la cercana relación de las mujeres con los medios de existencia y fuentes de vida para la organización de las economías de sustento, no como lugar esencial, sino como una condición histórica, les ha implicado que sean las que generalmente se encuentren en la primera línea de la defensa de sus territorios y soporten de manera desproporcionada en sus cuerpos, las consecuencias socioecológicas del desarrollo capitalista.

Frente a este problema, tanto en ámbitos académicos como militantes, se ha venido denunciando la invisibilidad de los impactos que las mujeres experimentan y han empezado a generar metodologías y registros de aquellas violencias específicas y diferenciadas, que han quedado oscurecidas porque su aparición tiende a desvincularse de su labor política, y suelen relacionarse con problemas de su vida privada o como producto de la violencia feminicida generalizada a nivel nacional que sufrimos todas en los distintos ámbitos de nuestras vidas (OLIVERA, 2019).

En diversas investigaciones feministas se ha constatado que la violencia contra las mujeres en contextos de defensa territorial, tiene un contenido político y contrainsurgente, ${ }^{7}$ en tanto busca agredirlas, disciplinarlas, estigmatizarlas, atacarlas y hasta eliminarlas como una forma de control ante la insubordinación, indisciplina o incumplimiento del rol de género que socialmente se espera de ellas (amas de casamadres- esposas), así como para difundir un mensaje de dominio sobre los territorios, a partir de atacar sus cuerpos (CARVAJAL, 2016; BELAUSTEGUIGOITIA Y SALDAÑAPORTILLO, 2015). La violencia contra las mujeres además de una acción de disciplinamiento hacia sus propios cuerpos, es también un modo de disuadir y descontrolar al conjunto, de inhibir los procesos organizativos cargando a las tramas comunitarias de dolor y ansiedad. Se trata de obligar a los cuerpos y comunidades agredidas a aceptar y acatar las disposiciones ajenas (GUTIÉRREZ, SOSA, REYES, 2019).

\footnotetext{
${ }^{7}$ En México, dos casos emblemáticos de este contenido contrainsurgente, han sido el de Inés Fernández Ortega y Valentina Rosendo Cantú, mujeres tlapanecas violadas por efectivos del ejército mexicano en 2002 y el de las mujeres de Atenco que fueron violadas y torturadas sexualmente durante la represión en dicho lugar en 2006. Ambos casos han sido presentados ante la Corte Interamericana de Derechos Humanos (HERNÁNDEZ, 2015, 81- 82, MENDOZA GALÁN, 2016).
} 


\section{Las luchas múltiples de las mujeres en defensa de la vida: protagonismos femeninos}

En medio de los impactos del extractivismo en los territorios amenazados y afectados, ha ido creciendo el mapa de resistencias en todo la geografía mexicana, protagonizadas principalmente por comunidades indígenas y campesinas, y otros procesos de autoorganización de habitantes o afectados ambientales en las ciudades. Un grupo de investigadores del Instituto de Investigaciones en Ecosistemas y Sustentabilidad de la UNAM ha identificado al menos, 560 conflictos socioecológicos en el periodo de 2012 a 2017. Estos conflictos fueron mapeados, geo-referenciados y clasificados en diez categorías según la problemática. La lista la encabezan los conflictos generados por la minería (173 conflictos), seguidos por los del agua (86), de energía (74), los causados por los proyectos mega-turísticos (49), los provocados por la expansión urbana (38), forestales (37), de carácter agrícola (35), por residuos tóxicos y peligrosos (34), por la construcción de carreteras (16), pesqueros (10) y biotecnológicos, básicamente por la introducción de maíz y soya transgénicos (8). Cada conflicto supone la afectación de núcleos humanos y de sus recursos locales, tales como problemas de salud, invasión o desposesión de territorios y propiedades, destrucción de bosques y selvas, contaminación de aire, suelo o agua, disrupción de cuencas y sus sistemas hidrológicos, afectación de mantos freáticos, lagunas, ríos o lagos, destrucción de fauna y flora y daños a los sistemas agrícolas, ganaderos y pesqueros (TOLEDO, 2018).

Una tendencia que hemos podido obervar en los procesos de resistencia, es que la llegada de los proyectos de despojo se experimenta como un momento que pone en peligro la vida y su reproducción (COMPOSTO, NAVARRO 2014, NAVARRO, 2015, LINSALATA, 2016). El sentido de emergencia y afectación que se activa, generalmente va re-tejiendo formas de enlace y generando nuevos y a veces inéditas alianzas y acuerpamientos comunitarios, como es la emergencia de ciertos protagonismos femeninos, con posibilidad de empujar procesos críticos de reflexión, cuestionamiento y alteración de las formas anteriores de relacionamiento.

A continuación, en el marco de tales procesos de organización y recomposición comunitaria, no exentos de conflicto y tensión, me interesa proponer una mirada que 
indague en la emergencia de una politicidad protagonizada por mujeres que resisten y luchan por garantizar la sostenibilidad y la reproducción de la vida, en el contexto de la resistencia a las violencias extractivistas.

En México, como ha sido la tendencia en América Latina, las mujeres no han sido reconocidas como titulares de la tierra por derecho propio (VÁZQUEZ, 2001). Aunque en los últimos 17 años, ha habido una ligera tendencia que apunta al aumento de mujeres con derechos agrarios ${ }^{8}$, de acuerdo con los datos del Registro Agrario Nacional, de cada 10 personas con derechos sobre la tierra, ni siquiera tres son mujeres (MIRANDA, 2019).

Sin duda, estos datos evidencian que la estructura agraria en nuestro país, está diseñada para que los varones concentren el derecho al uso, usufructo y sucesión de las tierras. Sólo en limitados casos las mujeres pueden tener este acceso, ya sea mediante la herencia de un varón, -el padre o el marido-, por vía contractual o, por la constitución de nuevos ejidos, pero siempre y cuando se cuente con el previo reconocimiento de la asamblea ejidal o de comuneros, integrada mayoritariamente por hombres (DE MARÍA, $\mathrm{s} / \mathrm{a})$.

Cabe aclarar que si bien el acceso legalmente reconocido de las mujeres a la tierra es minoritario, eso de ninguna manera significa que no intervengan sustancial y cotidianamente en los ámbitos productivos, además de la colosal cantidad de tareas en lo reproductivo. Esto es, aun sin derechos reconocidos, es creciente su participación en el desarrollo de toda clase de actividades agrícolas, ganaderas, forestales, para garantizar el sustento de sus familias y comunidades.

Además, en las últimas décadas, la sobrecarga de trabajo de las mujeres, se viene intensificando por las políticas neoliberales de retiro de los apoyos gubernamentales al campo, el desplazamiento de los hombres, a partir del incremento de la migración hacia las ciudades y a Estados Unidos, su integración al crimen organizado, la multiplicación del número de desaparecidos y asesinados por la llamada "Guerra contra el narcotráfico",

\footnotetext{
${ }^{8}$ En un estudio realizado por la Organización de las Naciones Unidas para la Alimentación y la Agricultura (FAO) y el Fondo Internacional de Desarrollo Agrícola (FIDA), se señala que en lo que va del siglo se cuadriplicó o creció en 406 por ciento el número de mujeres con derechos agrarios, es decir, que legalmente son dueñas de las tierras que trabajan, sea como ejidatarias o propietarias privadas, al pasar de 458 mil 652 en 2001 a un millón 865 mil 55 en 2017, de las cuales más de la mitad se ubican en los estados de Oaxaca, Veracruz, Chiapas, Guerrero, Puebla y estado de México. Ver: González, Susana "Mujeres del campo trabajan más y reciben menor pago que hombres: FAO" (La Jornada, 2019).
} 
el aumento de los despojos de los medios de vida y la criminalización cada vez más extendida de los defensores de los territorios.

Este aumento y diversificación de las cargas laborales es un fenómeno vinculado a la reproducción histórica de la división sexual del trabajo y los mandatos de género "naturales y obligatorios" bajo los cuales las mujeres aparecen como las responsables de las labores domésticas y de sostenimiento de la vida, sin que se les reconozca en ello, la realización de un trabajo productivo. Recientemente la FAO, informó que las mujeres tienen una carga de trabajo no remunerado de 68.7 horas por semana y sólo 11.4 horas de trabajo remunerado, mientras los hombres tienen 45.5 horas semanales de trabajo remunerado y sólo 23.5 horas de trabajo no remunerado, así que la brecha de género es de 34.1 horas de trabajo no remunerado (GONZÁLEZ, 2019).

Por si esto fuera poco, estas desigualdades se profundizan aún más con el avance del extractivismo, como sucede con las comunidades que han sido despojadas o limitadas de sus fuentes de sustento. En estas situaciones, las mujeres tienen que lidiar con aquellos que enferman a causa de la contaminación petrolera, debido a que el agua que usan para cocinar, lavar, limpiar y regar está contaminada, cuando han sido despojadas o limitadas de sus fuentes de sustento, tienen que recorrer distancias mucho más largas a las acostumbradas, o administrar con enormes apuros los ingresos monetarios, en caso de tenerlos, para comprar y hacer rendir el agua y otros insumos adquiridos para satisfacer las necesidades más acuciantes (SANKEY Y CÁRDENAS, 2013).

Las afectaciones a la salud humana y del ecosistema, son otro síntoma del avance destructivo que provoca la violencia extractivista. En estos casos, muchas mujeres están enfrentando mayor carga de trabajo para cuidar y ayudar a sanar a los enfermos, generalmente a costa de ellas mismas. En algunos territorios donde ya se enfrenta un grado de afectación mayor o de sufrimiento ambiental, las mujeres han comenzado procesos de trabajo preventivo y de epidemiología popular, a partir de la recuperación de saberes tradicionales y la apropiación de otros conocimientos y generación de datos e información científica para comprender las enfermedades que se padecen. Un caso sobresaliente es la investigación sobre contaminación atmosférica de micropartículas de metales pesados y pesticidas junto con la propuesta de salud preventiva que ha generado 
la Agrupación Un Salto de Vida, y en particular Graciela González, en la zona conurbada de Guadalajara, en el contexto del desastre socioambiental que la industria ha generado en su territorio (GONZÁLEZ, 2017).

El acompañamiento emocional y el seguimiento jurídico y político que requiere la lucha por la liberación de los familiares presos, criminalizados y a veces desaparecidos o asesinados por su implicación con los procesos de defensa territorial, es otra de las actividades que se suma a la larga lista de trabajos y que generalmente son poco visibles. Un ejemplo de esto, es la lucha de las mujeres del Consejo de Ejidos y Comunidades Opositores a la Presa la Parota (CECOP) por la liberación de 35 de sus familiares, quienes fueron injustamente encarcelados y torturados en junio de 2018. Esta situación las ha hecho asumir jornadas de hasta tres turnos de trabajo para sostener a sus familias y cubrir los gastos legales y de los traslados al Penal de las Cruces en Acapulco donde los presos políticos se encuentran (GIMÉNEZ, 2019).

Con todo lo anterior, se hace evidente que las comunidades están enfrentando una crisis de la reproducción social (FEDERICI, 2013; NAVARRO, LINSALATA, 2014), desatada por múltiples ataques contra las bases materiales y formas de subsistencia que garantizan su existencia, y que como se ha documentado ampliamente, las mujeres son afectadas de manera diferenciada y desigual (SALAZAR, 2017, CARVAJAL, 2017). Esto sucede, porque como diversas luchas ecofeministas han denunciado desde la década de los 70 hasta la actualidad, las mujeres suelen enfrentar mayores situaciones de vulnerabilidad, porque al ser las principales responsables de la reproducción de sus familias, se encuentran en una relación de mayor proximidad con los medios de subsistencia, y por lo tanto de mayor afectación, por los despojos múltiples de las distintas ofensivas extractivistas (MELLOR, 2000, SHIVA, 2004).

En distintas latitudes de Abya Yala, y especialmente en Mesoamérica, desde el feminismo comunitario territorial y las mujeres que vienen enfrentando distintos procesos de extracción y expropiación de sus medios de existencia, hablan del cuerpo- territorio para reconocer el cuerpo propio, en conexión con el tejido de la vida y en interdependencia con el territorio que habitan (CABNAL, 2019; Colectivo Miradas Críticas, 2017). Desde este modo de ver, las mujeres no sólo han ido identificando los despojos, explotaciones y afectaciones al territorio- tierra del que son parte, sino también 
aquellas lógicas de dominio sobre sus propios cuerpos en su dimensión física, emocional y espiritual, encontrando que hay un continuum y nada está separado. El cuerpo no está aislado o deambulando en el vacío, sino que está situado e interconectado con la red de la vida. La defensa de la vida, experimentada desde el cuerpo, va reconociendo las batallas y las marcas en los cuerpos individuales y colectivos por el hecho colonial, patriarcal y capitalista, lo que se expresa en la consigna: "mi cuerpo como primer territorio de defensa", pero también luchando por cuidar, sanar, recuperar y reapropiarse del cuerpo- territorio que históricamente se les ha querido despojar.

Desde esta experiencia sensible, se va habilitando un modo de ver y sentir la penetración del capitalismo-patriarcal y colonial, en el que el cuerpo, más que instancia de subjetivación individual, se concibe como una escala (GARCÍA TORRES, et.al., 2020) en la que se reconoce la experiencia singular que critica la opresión y se reafirma interdependiente y consciente de las distintas pieles corporales en las que se habita en la trama de la vida.

En el Seminario de Entramados Comunitarios y Formas de lo Político, hemos ido entendiendo que en el despliegue del modo de producción capitalista sobrevino un régimen específico de producción material y simbólica del cuerpo, siempre mediado por las relaciones de saber-poder comprometidas con la acumulación. ${ }^{9}$. Silvia Federici, en el Calibán y la Bruja, documenta cómo con el capitalismo, asistimos a una gran mutación antropológica del cuerpo para transformar las potencias de los individuos en fuerza de trabajo, mediante la alianza entre el Estado, la iglesia y el poder científico. Este gran proceso de disciplinamiento implicó una batalla contra el cuerpo, el despojo de sus saberes y su disociación, codificando la Razón 'como lo mejor' y al cuerpo 'como lo más bajo' (FEDERICl, 2014). Bajo esta operación, el Estado ha buscado sistemáticamente privatizar el cuerpo de las mujeres para convertirlo en el principal terreno de explotación, es decir, la producción de un "cuerpo máquina para la procreación" de las nuevas generaciones de trabajadores como garantía de la acumulación (FEDERICI, 2020). Este

\footnotetext{
9 Agradezco a las compañeras de Seminario de Entramados Comunitarios y de la Optativa de profundización temática "Mujeres, cuerpos-territorios y patriarcado capitalista. Miradas críticas desde la perspectiva de la interdependencia" del Posgrado de Sociología del ICSyH BUAP, y en especial, a Lucia Linsalata, Ana Laura Suárez, Pilar Muñoz, Pilar Mármol, Verónica Barreda y Guadalupe Macías, para pensar estas cuestiones.
} 
proceso de enajenación y expropiación, ha supuesto un modo de producir el cuerpo como objeto de otros y en función de otros, y por tanto, como instancia lejana, extraña y sin posibilidad de determinar plenamente.

Ciertamente, los feminismos y las actuales luchas de las mujeres contra las violencias en distintos territorios, vienen impugnando esa experiencia de enajenación y expropiación, que pueden llegar a compartir lo que Lorena Cabnal llama "la recuperación consciente del primer territorio cuerpo" (CABNAL, 2019, 129). Este esfuerzo de recuperación que es al mismo tiempo de reapropiación "pone en escena la disputa por la soberanía de los cuerpos (...) de esos cuerpos que históricamente fueron declarados no soberanos. Sentenciados como no aptos para decidir por sí mismos, es decir: de los cuerpos tutelados" (GAGO, 2019, 21). En diálogo con la brasileña Suely Rolnik, la reapropiación opera como una re- conexión con los saberes del cuerpo y una reafirmación subjetiva del ser viviente que todxs somos, afectadxs por los efectos de las fuerzas del mundo (ROLNIK, 2019).

Habitar nuestros cuerpos de ese modo, como proceso y no como un lugar al cual se llega sin más, habilita una forma sensible de conocer del mundo que busca hacerse cargo creativa y colectivamente de los malestares, los dolores, las violencias, las enfermedades, los temores, el gozo y la alegría necesaria para sostener la vida. Desde diversos modos colectivos de r-existencia ${ }^{10}$, las mujeres hacen de los saberes del cuerpo un poder que subvierte las obediencias que se inoculan debajo y por fuera de las pieles que habitamos. A pesar de que hay mucho dolor, juntas somos mujeres mas fuertes, expresan mujeres en el "Encuentro de Mujeres Defensoras del Territorio" en San Cristóbal Amoltepec, Tlaxiaco y en el "Encuentro de mujeres: entrelazando relatos y territorios" a principios de noviembre del 2019, en el territorio rebelde de Guelatao, Oaxaca en México.

En estos contextos, resaltan los modos en los que las mujeres se han ido acuerpando autónomamente para conversar sobre lo que enfrentan, tejer estrategias juntas y poner en el centro una práctica de cuidado y sanación que las fortalezca. Esto es muy importante si recordamos que la amistad entre mujeres desde los albores del

\footnotetext{
10 "Los pueblos resisten porque existen; por tanto, r-existen”. Porto- Gonçalves, Carlos, "Lucha por la Tierra "Ruptura metabólica y reapropiación social de la naturaleza”, Polis. Revista Latinoamericana, núm. 45, 2016 , p. 8.
} 
capitalismo, fue estigmatizada en el marco de la cacería de brujas, como proceso inherente de la degradación y fractura del poder social entre mujeres (FEDERICI, 2014, 256). Como plantea Silvia Federici, los espacios de mujeres son cruciales,

en el descubrimiento de la fuerza propia, pero también en las formas en las que nos autodestruimos, auto-desvalorizamos e interiorizamos el capitalismo. Este es un proceso colectivo que no podemos hacer solas. Una generalmente no se mira con sus propios ojos, se mira a través de los otros. La fuerza del feminismo radica en cambiar la forma de mirarnos a nosotras mismas, por ejemplo a través de la mirada de nuestras hermanas. Cuando te ves a través de la mirada de las mujeres que amas y con las que luchas, es muy diferente a cuando te miras desde fuera (NAVARRO Y GUTIÉRREZ, 2017, 122).

En México, un conjunto de mujeres defensoras de sus territorios de todo el país, han lanzado la Campaña colaborativa "Juntas Logramos Más" en la que se viene construyendo una comunidad narrativa ampliada desde donde crear, compartir y tejer relatos sobre las mujeres y las luchas frente al despojo para nombrar y visibilizar su participación y aportes en la defensa del territorio, así como compartir herramientas de autocuidado de las mujeres defensoras. ${ }^{11}$

En definitiva, en los últimos años, son muchos los espacios entre mujeres que se han creado para impulsar procesos de espiritualidad, sanación y cuidado colectivo, como instancias necesarias y estratégicas para sostener la lucha en las condiciones de despojo que se están librando, pero también para problematizar los términos de las relaciones de interdependencia de las mujeres con sus tramas colectivas. "Nos dábamos cuenta que el cuidado que damos, no lo recibimos de modo proporcional en relación con lo que nosotras necesitamos para garantizar nuestro bien-estar en términos físicos, emocionales y espirituales" (GARCÍA et al, 2020).

A partir de problematizar esta cuestión, en el sureste mexicano, se creó la Casa Serena, un espacio de descanso y sanación para defensoras y activistas integrantes de las redes y articulaciones nacionales en El Salvador, Guatemala, Honduras, Nicaragua y México, como parte de la Iniciativa Mesoamericana de Mujeres Defensoras de Derechos humanos (Consorcio Oaxaca, 2016).

Hablar de la producción de protagonismos femeninos en las luchas en defensa de

${ }^{11} \mathrm{https}: / /$ lasandiadigital.wixsite.com/ 
la vida, está relacionado con reconocer las múltiples e intensivas luchas que las mujeres están librando, tanto en los tiempos ordinarios y extraordinarios de la existencia, para garantizar la reproducción de la vida: alimentando, administrando, cocinando, comunicando, cosechando, criando, cuidando, curando, informando, organizando, platicando, reparando, sanando o sembrando una existencia que se sabe frágil y al mismo tiempo interdependiente. Pero también llamo la atención sobre las formas renovadas que están adquiriendo dichos protagonismos: tomar la palabra en una asamblea, dar una entrevista a algún medio de comunicación, asumir tareas organizativas o intervenir de manera inédita en espacios que tradicionalmente no habían habitado, poner el cuerpo ante la amenaza inminente de las máquinas, e impidiendo la llegada del personal corporativo o estatal, extraño a la comunidad. Las imágenes de las mujeres zapatistas de Chenalhó en Chiapas saliendo a detener el avance del ejército mexicano sobre sus comunidades en 1998 y, las mujeres de Cherán en 2011, que organizaron el levantamiento de sus comunidades, cansadas de las extorsiones, secuestros y asesinatos en manos del crimen organizado y los talamontes, son muestras de ello.

Cabe señalar que mi apuesta analítica de dar visibilidad y reconocer el carácter imprescindible del trabajo de las mujeres en la autoreproducción de la lucha, término que Cristina Vega (2019) nos propone para pensar la reproducción de la vida como un asunto político y en el que la trama en cuestión trata de hacerse cargo, no busca reforzar una ética reaccionaria del cuidado, ni profundizar los términos de la división sexual del trabajo capitalista-patriarcal y colonial. A este respecto, Amaia Pérez nos advierte que la lógica de sostenibilidad de la vida se pervierte en una ética reaccionaria del cuidado, cuando se parte de imponer a las mujeres la responsabilidad de sacar adelante la vida (PÉREZ, 2014).

En todo caso me pregunto si el antagonismo social que en distintos territorios se está desplegando contra la violencia extractivista, está alterando los términos tradicionales de relacionamiento al interior de las tramas comunitarias. En diálogo con el trabajo del Colectivo Miradas Críticas del Territorio desde el Feminismo (2020), hemos visto que pueden abrirse horizontes de des-patriarcalización para alcanzar nuevas formas de relación en las que las intervenciones de las mujeres sean reconocidas y reorganizadas, y como plantea Raquel Gutiérrez (2018), se generen renovados 
equilibrios comunitarios. Pero también sabemos que pueden actualizarse procesos de repatriarcalización de los territorios, a partir del entrelazamiento de las distintas violencias que garantizan el ciclo de expansión capitalista (CRUZ, 2020), lo que incluye la afirmación de pactos y reacciones violentas de los hombres que, sienten cuestionada su autoridad y pretenden un regreso a la "normalidad" que brindaba el orden anterior.

\section{A modo de cierre}

Como hemos visto, el avance de los regímenes extractivistas y las violencias del complejo capitalista, patriarcal y colonial afectan de manera desigual y diferenciada las vidas y cuerpos de las mujeres. Queda pendiente seguir analizando cómo estas violencias están profundizando y lanzando procesos de re-patriarcalización a partir de actualizar formas previas de dominación y explotación contra las mujeres, e inhibiendo o desactivando su protagonismo y participación en las decisiones relacionadas con la vida en sus territorios.

Lo cierto es que en medio de esta crisis de la reproducción, las mujeres vienen organizando una serie de estrategias y esfuerzos para defender sus territorios y tramas comunitarias. En ese sentido, la apuesta por pensar la producción de protagonismos femeninos en las luchas socioecológicas, en contextos de antagonismo social, está relacionada con reconocer el carácter renovado y actualizado de las múltiples e intensivas luchas que las mujeres están librando. Autoreproducir la lucha, desde estos protagonismos femeninos, está implicando cultivar una política ligada a la vida y poner en juego las capacidades políticas, espirituales, físicas y emocionales que se tienen, para reconstruir los términos de la interdependencia y disputar las condiciones que hagan posible una vida digna en sus ecosistemas.

\section{Referencias}

BELAUSTEGUIGOITIA, M.; Saldaña- Portillo, M.J. Desposesión: género, territorio y luchas por la autodeterminación, México: UNAM- PUEG, 2015.

CABNAL, L. Acercamiento a la construcción de la propuesta de pensamiento epistémico de las mujeres indígenas feministas comunitarias de Abya Yala. en: Minervas (coord.), Momento de paro. Tiempo de Rebelión. Montevideo: Minerva Ediciones. Una editorial propia, 2019. 
CARVAJAL, L.M. Extractivismo en América Latina: impacto en la vida de las mujeres y propuestas de defensa del territorio, Bogotá: Fondo Acción Urgente, 2016.

COLECTIVO MIRADAS CRÍTICAS DEL TERRITORIO DESDE EL FEMINISMO, Mapeando el cuerpo-territorio. Guía metodológica para mujeres que defienden sus territorios. Ecuador: Colectivo Miradas Críticas del Territorio desde el Feminismo- Red Latinoamericana de Defensoras de Derechos Sociales y Ambientales- Instituto de Estudios Ecologistas del Tercer Mundo- CLACSO, 2017.

CONSORCIO OAXACA, Guía de acompañamiento. Oaxaca: Casa La Serena, 2016.

COMPOSTO, C. y Navarro Trujillo, M. (coords.) Territorios en disputa. Despojo capitalista, luchas en defensa de los bienes comunes naturales y alternativas emancipatorias para América Latina. Ciudad de México: Bajo Tierra Ediciones, 2014.

CRUZ, Delmy, Bayón, Manuel (coords.), Cuerpos, territorios y feminismos, QuitoCiudad de México: Ediciones Abya Yala, 2020.

DE ANGELIS, M. Marx y la acumulación primitiva: el carácter continuo de los 'cercamientos' capitalistas, Theomai, Buenos Aires: № 26, noviembre de 2012.

DE MARÍA, A. El acceso de las mujeres rurales a la tenencia de la tierra: el caso de México, México: Estudios Agrarios, s/año.

DELLA Colleta, R. Un feminicidio abre viejas heridas en Cherán, ícono del autogobierno en México, El País, México: 19 enero 2018. Disponible en: https://elpais.com/internacional/2018/01/19/america/1516332208_984179.html

EL PAÍS. Asesinada en México una ecologista que defendía la preservación de un manglar, El País, México: 8 junio 2012.

ERPEL Jara, Á. Mujeres en defensa de los territorios. Reflexiones feministas frente al extractivismo, Valparaíso: Fundación Heinrich Böll, 2018.

FEDERICl, S. Beyond the Periphery of the Skin: Rethinking, Remaking and Reclaiming the Body in Contemporary Capitalism, Oakland: PM Press, 2020.

FEDERICI, S. Calibán y la bruja: mujeres, cuerpo y acumulación originaria, Madrid: Traficantes de Sueños, 2014.

FEDERICI, S. Revolución en punto cero. Trabajo doméstico, reproducción y luchas feministas, Madrid: Traficantes de Sueños, 2013.

FISHER, Steve y Malkin, Elizabeth, "Un Chernobyl en cámara lenta”, New York Times, 1 enero 2020. Disponible en: https://www.nytimes.com/es/2020/01/01/espanol/ america- 
latina/mexico-medioambiente-tmec.html

FRAGA, E. El pensamiento binario y sus salidas. Hibridez, pluricultura, paridad y mestizaje. Revista Estudios Sociales Contemporáneos, N9 / IMESC-IDEHESICONICET Octubre 2013.

GAGO, Verónica, La potencia feminista o el deseo de cambiarlo todo. Buenos Aires: Tinta Limón, 2019

GARCÍA-TORRES, Miriam; Vázquez, Eva; Cruz, Delmy Tania; Bayón, Manuel,"Extractivismo y (re)patriarcalización de los territorios", en: Cruz, Delmy, Bayón, Manuel (coords.), Cuerpos, territorios y feminismos, Quito- México: Ediciones Abya Yala, 2020

GIMÉNEZ, I. Guerrero: la resistencia de las mujeres del CECOP, Contralínea, México: 3 junio 2019. Disponible en: https://www.contralinea.com.mx/archivo-revista/2019/06/03/ guerrero-la-resistencia-de-las-mujeres-del-cecop/

GLOBAL WITNESS, Defender la tierra. Asesinatos globales de defensores/as de la tierra y el medio ambiente en 2016, Global Witness, 2017. Disponible en:https://www.globalwitness.org/en/campaigns/environmental-\%20activists/defender-latierra/

GONZÁLEZ, M. Encuentran metales pesados y bacterias en aire y suelo en el Salto y Juanacatlán, Portal Universidad de Guadalajara, Guadalajara: octubre 2017. Disponible en:http://www.udg.mx/es/noticia/encuentran-metales-pesados-y-bacteriasen-aire-y-suelo-de-el-salto-y-juanacatlan

GONZÁLEZ, S. Mujeres del campo trabajan más y reciben menor pago que hombres: FAO, La Jornada, México: 18 junio 2019. Disponible en: https://www.jornada.com.mx/ultimas /2019/06/18/mujeres-del-campo-trabajan-mas-yreciben-menor-pago-que-hombres-fao-5946.html?fbclid=IwAR2-svqPnGD-

jIC4N2v5fjJo6lpECt-4qblJsJzh9h_vJzlg41Gw4hsxs3E

GUDYNAS, E. Extracciones, extractivismos y extrahecciones", Centro Latino Americano de Ecología Social, Montevideo: 2013. Disponible en: http://ambiental.net/wpcontent/uploads/2015/12/GudynasApropiacionExtractivismoExtra heccionesOdeD2013.pdf

GUTIÉRREZ Aguilar, R; Reyes, I.; Sosa M. El entre mujeres como negación de las formas de interdependencia impuestas por el patriarcado capitalista y colonial. Reflexiones en torno a la violencia y la mediación patriarcal. Revista Heteritopías, UNC, 2017

GUTIÉRREZ, R. La lucha de las mujeres contra todas las violencias: reunir fragmentos para hallar sentido, en South Atlantic Quarterly, Estados Unidos: Duke 
University Press, 2018.

GUTIÉRREZ, R y Navarro, M. L. Producir lo común para sostener y transformar la vida. Algunas reflexiones desde la clave de la interdependencia, Confluencias. Revista Interdisciplinar de Sociologia e Direito, Brasil: vol. 21, no. 2, agosto 2019.

HERNÁNDEZ, A. Cuerpos femeninos, violencia y acumulación por desposesión", en: Belausteguigoitia, Marisa/ Saldaña- Portillo, María Josefina, Desposesión: género, territorio y luchas por la autodeterminación, México: UNAM- PUEG, 2015.

LA JORNADA ZACATECAS, Encuentran cuerpo de una mujer desaparecida en San Luis Potosí, La Jornada, Zacatecas: 24 marzo 2020.

LANDER, E. Ciencias sociales: saberes coloniales y eurocéntricos, Lander, E. (comp.), La colonialidad del saber: eurocentrismo y ciencias sociales. Perspectivas latinoamericanas, Buenos Aires: CLACSO, 2003.

LEFF, E. "La Ecología Política en América Latina: un campo en construcción”, en Héctor Alimonda (comp.), Los tormentos de la materia: aportes para una ecología política latinoamericana, Buenos Aires: Clacso, 2006.

LINSALATA, L. Lo comunitario-popular en México: desafíos, tensiones y posibilidades. México: Instituto de Ciencias Sociales y Humanidades "Alfonso Vélez Pliego", Benemérita Universidad Autónoma de Puebla; 2016.

MACHADO Aráoz, H. Del debate sobre el "extractivismo" hacia una Ecología Política del Sur. Una mirada; una propuesta" en: Despojo capitalista y luchas comunitarias en defensa de la vida en México. Claves desde la Ecología Política, Navarro, Mina Lorena y Fini, Daniele (coords.), Puebla: Instituto de Ciencias Sociales y Humanidades "Alfonso Vélez Pliego", Benemérita Universidad Autónoma de Puebla, 2016.

MACHADO Aráoz, H. Clase Regímenes extractivistas, Curso Ecología Política de CLACSO, Argentina: 2019.

MELLOR, M. Feminismo y Ecología, México: Siglo XXI, 2000/

MENDOZA Galán, C. Defensoras del territorio bajo amenaza, Animal Político, México: 5 septiembre 2016. Disponible en: https://www.animalpolitico.com/blogueros-degenerando/2016/09/05/amenaza-mujeres-guerreras-defensa-del-territorio/

MIES, M. Patriarcado y acumulación a escala mundial, Madrid: Traficantes de Sueños, 2019.

MIRANDA, F. En México, la tierra no es de las mujeres: sólo hay $26 \%$ de ejidatarias, El Universal, México: 4 marzo 2019. Disponible en: https://oaxaca.eluniversal.com.mx/ especiales/04-03-2019/en-mexico-la-tierra-no-es-de-las-mujeres-solo-hay-26-de- 
ejidatarias\#imagen-1.

MOORE, J. W. Capitalism in the web of life. Ecology and accumulation of capital, EUA: Editorial Verso, 2015.

NAVARRO, M. L. y Linsalata, L. Crisis y reproducción social: claves para repensar lo común. Entrevista a Silvia Federici, Revista OSAL, Buenos Aires: No. 35, OSAL, 2014.

NAVARRO Trujillo, Mina Lorena, Luchas por lo común. Antagonismo social contra el despojo capitalista de los bienes naturales en México, Ciudad de México: Bajo Tierra Ediciones, ICSyH BUAP, 2015.

NAVARRO, Mina Lorena y Gutiérrez, Raquel, "Diálogos entre el feminismo y la ecología desde una perspectiva centrada en la reproducción de la vida. Entrevista a Silvia Federici”, Revista Ecología Política, Icaria Editorial, Cataluña, 2017.

NAVARRO TRUJILLO, M.L. y Gutiérrez, R. 2018. "Claves para pensar la interdependencia desde la Ecología y los Feminismos", Bajo el Volcán, Puebla: número 28, marzo- agosto.

OCAMPO, Sergio, "Asesina a dirigente ecologista y a uno de sus hijos", La Jornada, 29 noviembre 2012.2 Disponible https://www.jornada.com.mx/2012/11/29/estados/036n1est

OLIVERA, Beatriz, "La violencia invisibilizada hacia las defensoras de la tierra y el territorio", Animal Político, México: 2019.

PÉREZ Orozco, Amaia, Subversión femenina de la economía, Madrid: Traficantes de Sueños, 2014.

PORTO-GONÇALVES, Carlos, "Lucha por la Tierra Ruptura metabólica y reapropiación social de la naturaleza", Polis. Revista Latinoamericana, núm. 45, 2016, p. 8.

RELATOR ESPECIAL DE NACIONES UNIDAS, Informe sobre violaciones a los derechos humanos al agua potable y al saneamiento en México, Presentado al Relator Especial de Naciones Unidas sobre los derechos humanos al agua potable y al saneamiento en ocasión de su Misión a México en mayo de 2017, pp. 89-92. Disponible en: http://www.comda.org.mx/wp-content/uploads/2019/01/informe_DHAyS-2daedicion.pdf

RELATOR ESPECIAL sobre la situación de los defensores de los derechos humanos, Informe del Relator Especial sobre la situación de los defensores de los derechos humanos A/71/281, agosto de 2016, p. 20. Disponible en: https://www.protectingdefenders.org/sites/protecting-defenders.org/files/opendocpdf(4)_1.pdf 
ROLNIK, Suely, Esferas de la insurrección. Apuntes para descolonizar el inconsciente, Buenos Aires: Tinta Limón Ediciones, 2019.

SALAZAR, Amílcar, "Bety Cariño, a sesis años del asesinato de la activista" La Silla Rota,México, 26 abril 2016. Disponible en: https://lasillarota.com/bety-carino-a-seis-anosdel-asesinato-de- la-activista/110817

SANKEY, Kyla/ Cárdenas, Isabel, "Mujeres y reproducción social: la otra crisis del agua",Observatorio del Desarrollo, núm. 7, México, 2013. Disponible en: https://estudiosdeldesarrollo.mx/observatoriodeldesarrollo/numero-7/

SEGATO, Rita, La guerra contra las mujeres, Madrid: Traficantes de Sueños, 2016.

SEOANE, José, "Neoliberalismo y ofensiva extractivista: actualidad de la acumulación por despojo, desafíos de Nuestra América", Theomai, № 26, Buenos Aires, noviembre de 2012.

SHIVA, Vandana, Abrazar la vida, Madrid: horas y horas, 2004.

SVAMPA, Maristella, "Consenso de los Commodities y lenguajes de valoración en América Latina", Nueva Sociedad, 2013. Disponible en: http://nuso.org/articulo/consenso-de-los-commodities-y-lenguajes-de-valoracion-en-america-latina/.

SVAMPA, Maristella, Las fronteras del neoextractivismo en América Latina: conflictos socioambientales, giro ecoterritorial y nuevas dependencias, Alemania, Centro Maria Sibylla Merian de Estudios Latinoamericanos Avanzados en Humanidades y Ciencias Sociales, 2019.

TOLEDO, Víctor, "Mapeando las injusticias ambientales en México", Boletín de Prensa, México: 2018.

TZUL, Gladys, Sistemas de Gobierno Comunal Indígena: Mujeres y tramas de parentesco en Chuimeq'ena', Guatemala: Sociedad Comunitaria de Estudios Estratégicos y Centro de Investigaciones y Pluralismo Jurídico Tz'ikin, Editorial Maya Wuj, 2016

VÁZQUEZ García, Verónica, "Género y tenencia de la tierra en el ejido mexicano: ¿la costumbre o la ley del Estado?", Estudios Agrarios, México: 2001, p. 26. Disponible en: $\quad$ http://www.pa.gob.mx/publica/cd estudios/Paginas/autores/vazquez\%20 garcia\%20veronica\%20genero\%20y\%20tenencia\%20de\%20la\%20tierra.pdf

VEGA, C.; Martínez, R.; Paredes, M. Experiencias y vínculos cooperativos en el sostenimiento de la vida en América Latina y el sur de Europa. Madrid: Traficantes de Sueños, 2018. 